\title{
Research on Decision Support Service Model based on Big Data
}

\author{
Ahmed Rizk \\ Beni Suef University, Egypt \\ ahmed.rizk@nsst.bsu.edu.eg
}

\begin{abstract}
With the rapid development of big data, the potential value of data resources urgently needs to be tapped and utilized. More and more companies choose the form of alliances to realize the complementary advantages of data resources. Through the sharing of data resources of alliance members, it can flexibly support corporate decision-making according to market needs and provide decision-making support services for society more efficiently. Based on the analysis of the research status and related concepts of big data alliances, decision support, service models in various countries, this paper reveals the coupling mechanism of big data alliance decision support services based on the hypercycle theory. On this basis, according to the characteristics of user needs, two decision support service models of big data alliance based on complete user information and incomplete user information are constructed. Decision support service model based on complete user information, including user demand description, information search and matching, service plan formation and delivery and feedback, and interactive and follow-up service methods. Decision support service mode based on incomplete user information, including user demand mining, missing information supplementation, service plan formation, and delivery and feedback, and detailed consultation and multiple negotiation service methods. The Big Data Alliance focuses on promoting cooperation among various industries in the process of providing decision support services. Vigorously promote the application of big data and the technological achievements of the big data alliance in various industries, and realize the complementation of data resources in different industries and multiple dimensions. Promote the overall development level of member companies in the Big Data Alliance.
\end{abstract}

Keywords: Big data, Decision support, User information, Service model

\section{Introduction}

Big data, as another disruptive technological change in the IT industry after the Internet, the Internet of Things, mobile computing, and cloud computing, is leading a new wave of productivity growth and consumer surplus. In the big data environment, data and demand dualdriven decision-making pay more attention to the correlation between data resources and discover the potential value of data resources. To a greater extent, the excessive reliance on the decision-making power of domain experts is overcome, and the accuracy of decision-making is improved. Whether the decision is correct or not directly affects the survival and development of an enterprise. How to use data resource management for decision support services has become a key issue that needs to be resolved.

Article history:

Received (June 9, 2018), Review Result (July 21, 2018), Accepted (September 27, 2018) 
The Big Data Alliance (BDA), as a new form of an alliance organization, can not only realize the interactive sharing of data resources but also breakthrough data resource barriers to avoid risks caused by data resource islands. Marchand pointed out that companies should not only pay attention to technical issues but also focus on the resulting transformation of management decision-making models [1]. Having an advantage in data resources is equivalent to having an advantage in decision-making. From the traditional elite decision-making model to a nonlinear, uncertainty-oriented, bottom-up decision-making model, it is manifested in the expansion and downward movement of decision-making participants in the decision-making process such as pre-foresight, perception during the event, and feedback after the event. Traditional management decision-making is goal-driven decision-making, which focuses on analyzing the causal relationship of data resources. It often pays too much attention to details and lacks an overall grasp and understanding of the overall situation. It is no longer sufficient to respond to new demands in the big data environment. For enterprises to break through the barriers of data resources, obtain additional data resources, dig out the potential value of data resources, and serve for management decision-making, forming alliances has become an important choice. BDA focuses on serving companies from all walks of life to cooperate, vigorously promote the application of data resource technology in all walks of life, and promote the overall development level of the big data alliance. The Big Data Alliance insists on comprehensive aggregation, in-depth mining, and efficient application of data resources. Carry out comprehensive and in-depth cooperation and construct a data resource ecological chain to promote the healthy and innovative development of data resources, to better provide enterprises with decision support services.

This article, therefore, takes the big data alliance as the research context and the user needs as the starting point to create the decision support service model of the big data alliance. The Big Data Alliance integrates big data, the Internet, and other data resource processing technologies, and through continuous interaction and collaboration with users, the decision support process is service-oriented. To provide users with a pay-as-you-go, personalized, dynamic, innovative, and intelligent decision support service.

\section{Research status}

In the area of big data management research. Akoka pointed out that in terms of big data management applications, the Internet, cloud computing, and mobile social media should be combined to maximize the value of data [2]. Ali et al. send the data to a centralized server and use the existing business intelligence and big data analysis software for further processing and analysis to better manage the diverse data [3]. Correa et al. analyzed the existing intelligent measurement big data analysis and processing technology and explored its potential performance [4]. Mckay et al. put forward new ideas for big data management skills, by constructing accurate measurement models to optimize data processing speed and data standardization [5]. Golov and Manco have conducted research on big data management issues, constructed a big data management model, and proposed a highly standardized method [6][7].

In terms of big data application research. Manco et al. analyzed the traffic big data and obtained the probability of traffic accidents through the data analysis model [8]. Pramanika and John believe that B2B relationships are very important. They provide mutual benefits to offset the resource-intensive costs required for relationship establishment and maintenance. The results show that the impact of big data applications on enterprise product revenue is different [9][10]. Nils and others applied big data to the project implementation process and evaluated the indicators involved in the implementation process, and the results showed that the 
application of big data played a positive role in project implementation [11]. Chahine et al. put forward a hypothesis, through the analysis of medical big data, they believe that improving medical education can improve patient care, and clinical results prove the hypothesis [12].

In terms of the actual management of the Big Data Alliance. The Research Data Alliance (RDA) is an international organization [13] established in 2012 to provide a forum for researchers to identify and eliminate barriers to data sharing. RDA already has more than 3,000 individual members, more than 30 organization members, 47 interest groups, and 17 working groups. They all focus on research data sharing. They believe that interoperability is an example of data sharing, but it is not the only obstacle. [13]. Treloar et al. studied the reasons for the formation of the Data Alliance (RDA), the research status, the experience and lessons of the first year of operation, and the expected impact on data release and sharing [14]. Foreign research on big data alliances was earlier, and a batch of big data alliances was established to promote the dissemination and application of data resources. The New Jersey Big Data Alliance provides access to big data technology and expertise, promotes multi-institutional and publicprivate collaborative research, and strengthens New Jersey's network infrastructure construction to promote local economic development and enhance competitiveness. Fraunhofer Big Data Alliance is committed to biomedical research and development. Due to the complexity of data, application-independent data integration is not feasible. It is believed that data can be evaluated by machine learning algorithms to identify disease mechanisms or appropriate treatments, human-centered incremental interactive data integration, and high-throughput processes in life sciences. It is pointed out that the digital transformation in life sciences has led to more and more data that needs to be stored and analyzed appropriately to realize its huge potential in medical research and health care.

In terms of research on decision support methods. The D-S evidence theory proposed by Dempster AP is an important uncertainty reasoning method [15]. Rota G C improved it to make it more complete [16], Hua Z (2008) and others considered the focal elements that may appear in the incomplete information matrix, and ranked them according to the confidence interval of the alternatives [17]. In the current research, some scholars apply the method of distance measurement to decision-making problems. This method compares the alternatives with the ideal results and selects the one that is closest to the ideal results.

In the research of decision support systems. Peter proposed that computer applications will also develop in informed decision-making. Since then, many scholars have researched it, and then decision support systems have begun to be applied in all walks of life. First, decision support systems have been introduced in the securities industry, which can give investors suggestions to help them make decisions. Later, some scholars applied their intelligent learning to the decision support system, and the intelligent decision support system was born [18][19].

\section{Big data alliance service coupling mechanism and decision support service mode architecture}

\subsection{Reasons for the formation of big data alliance and organizational form}

Pateli proposed a concept of Alliance Expected Value (EAV) to analyze various cooperation states of alliances [20]. The members of the Big Data Alliance process data resources through the service platform, realize the sharing and interactive services of data resources, improve the overall utilization rate of data resources, and reduce the use cost of data resources through scale effects. The platform integrates the data resources provided by the member companies in the 
alliance, which improves the utilization value of data resources, and uses the innovative power of the alliance member companies to collaborate to create more data resources.

Regarding the classification of alliances, domestic and foreign scholars have classified them from different perspectives. The most representative classifications mainly include the following views:

1. From the perspective of the degree of participation of members: According to the degree of participation between alliance companies and the degree of alliance closeness, the types of strategic alliances can be divided into:

(a) Equity-based strategic alliances, that is, such alliance companies involve equity participation and cooperation through equity participation. Generally, there are two types of equity participation in the form of equivalence and mutual ownership. The cooperation between members of this type of alliance is very close, so the stability shown is relatively strong.

(b) Contract-type strategic alliances. This type of alliance is mainly based on alliances established by alliance companies. The alliance companies do not involve equity participation and are established on the premise of joint technology development or market development. Therefore, the formation and dissolution of contract-based strategic alliances are relatively flexible than equity-based strategic alliances.

2. From the perspective of mutual relations in the supply chain According to the mutual relations of alliance enterprises in the supply chain, the types of strategic alliances can be divided into:

(a) Vertical alliances are alliances composed of upstream and downstream enterprises in the product supply chain.

(b) Horizontal alliances are alliances formed by companies producing similar products at the same link in the product supply chain to avoid malicious competition and monopolize the market.

(c) Hybrid alliance, that is, the alliance formed by enterprises not only has the characteristics of the vertical alliance but also has the characteristics of the horizontal alliance, which is a comprehensive alliance.

3. From the perspective of alliance formation requirements Different types of strategic alliances can be divided into different types of strategic alliances:

(a) Production-oriented strategic alliances, that is, to reduce product manufacturing costs, alliance companies, to obtain scale advantages and economies of scope, jointly produce and manufacture products with other companies in the alliance. After the formation of this type of alliance, the organizational structure and management model of the member companies will not change, but it will focus on the production capacity of the alliance companies.

(b) Market-oriented strategic alliances, that is, alliance companies achieve the goal of breaking through market barriers, reducing product sales costs, and expanding market share through exchange and sharing of market sales channels. Such alliance companies have a high market share and specific sales channels, usually appearing in the form of price alliances and marketing alliances.

(c) Learning-oriented strategic alliance, that is, the alliance enterprises take new technology research and development as the premise, learn from each other in the process of collaborative 
research and development, and realize innovative organizational forms through knowledge transfer, sharing, and integration.

\subsection{Coupling mechanism of big data alliance decision support service based on hypercycle theory}

Decision-making problem refers to the problem that decision-makers make the best action plan based on the collected intelligence, through analysis and processing, in the design, selection, implementation, and other links. However, actual decision-making problems often involve complicated environments, elements, structures, functions, and models due to different factors such as the decision-making environment, degree of structure, decision-making goals, and nature of decision-making, making it difficult to make decisions with conventional methods. Based on its resources and technical advantages, the Big Data Alliance can solve complex decision-making problems for users that cannot be solved by conventional methods. To make more scientific and effective decision-making, the decision-making problems are classified as follows according to different standards, as shown in [Table 1].

Table 1. Classification of decision problems

\begin{tabular}{|c|c|}
\hline Classification standard & Content \\
\hline Degree of structure & Structured decision, semi-structured decision, unstructured decision \\
\hline Environment & Deterministic decision, risky decision, uncertain decision \\
\hline Business level & The strategic decision, campaign decision, tactical decision \\
\hline Target number & The single objective decision, multi-objective decision \\
\hline Decision method & $\begin{array}{c}\text { Qualitative decision, quantitative decision, qualitative and } \\
\text { quantitative comprehensive decision }\end{array}$ \\
\hline Number of decision-makers & Individual decision making, group decision making \\
\hline Decision location & Centralized decision-making, distributed decision-making \\
\hline Rationality & The rational decision, behavior decision \\
\hline $\begin{array}{c}\text { Continuity of decision-making } \\
\text { process }\end{array}$ & Phase decision, sequential decision \\
\hline $\begin{array}{c}\text { The concentration of decision- } \\
\text { making authority }\end{array}$ & Centralized decision-making, decentralized decision-making \\
\hline
\end{tabular}

The big data alliance decision support service has the following characteristics:

(1) Consistency of goals.

(2) Participation of multiple decision-making entities.

(3) High degree of resource sharing.

(4) The decision-making stages are interrelated.

(5) There is a need for sustainable development.

(6) Participation of decision support service platform.

(7) Rapid response to market opportunities.

(8) Professionalism of decision support services.

The Big Data Alliance takes advantage of its large number of decision-making resources and a variety of artificial intelligence technologies to transform the decision-making intelligence system of the Big Data Alliance into the user's central decision-making brain, provide users with the results of decision support services, and dig deeper into decision-making resources 
Causality. However, the results of these intelligent predictions need to undergo certain processing before they can be transformed into decision support service solutions that can be delivered to alliance users. The Big Data Alliance uses information analysis and processing capabilities and artificial intelligence technology to calculate and integrate the decision-making resources required for decision-making support services. In-depth exploration of the causal relationship behind decision-making resources promotes the release of the potential value of decision-making resources in the big data alliance and realizes further value appreciation.

(1) Conversion cycle reaction: The first level "conversion reaction cycle" is the initial cycle reaction, which is the process of reaction unit generating products under external action. The reaction unit generates new intermediate products under the action of the catalyst, and the intermediate products form new products through self-creation. The new products participate in the next conversion reaction under the action of the catalyst, thus forming a reaction cycle.

(2) Catalytic cycle reaction: In the process of providing decision support services by the Big Data Alliance, the new decision-support service resources, decision support service requirements, and platform services generated in the previous stage are all used as catalysts for the catalytic reaction cycle. At the same time catalyze the matching of supply and demand during the reaction. The catalytic reaction of the second level "catalytic reaction cycle" is based on the first level and consists of multiple conversion reaction cycles. In the first stage, selfreplication is continuously carried out, and the catalysis is generated from the catalyst so that multiple transformation reactions are fused and connected to form a cycle capable of autocatalytic reactions.

(3) Hypercycle: The third level of decision-making is "supercycle". The supercycle of the third level is the most advanced reaction, a complex reaction cycle composed of a continuous conversion reaction cycle and a catalytic reaction cycle. Hypercyclic reactions can create and replicate themselves, and each cyclic unit will continue to merge and cross-catalyze each other, making them more closely related. Hypercyclic reaction will continue to circulate and accumulate resources, thereby developing to a higher level. The supercycle process is shown in [Figure 1].

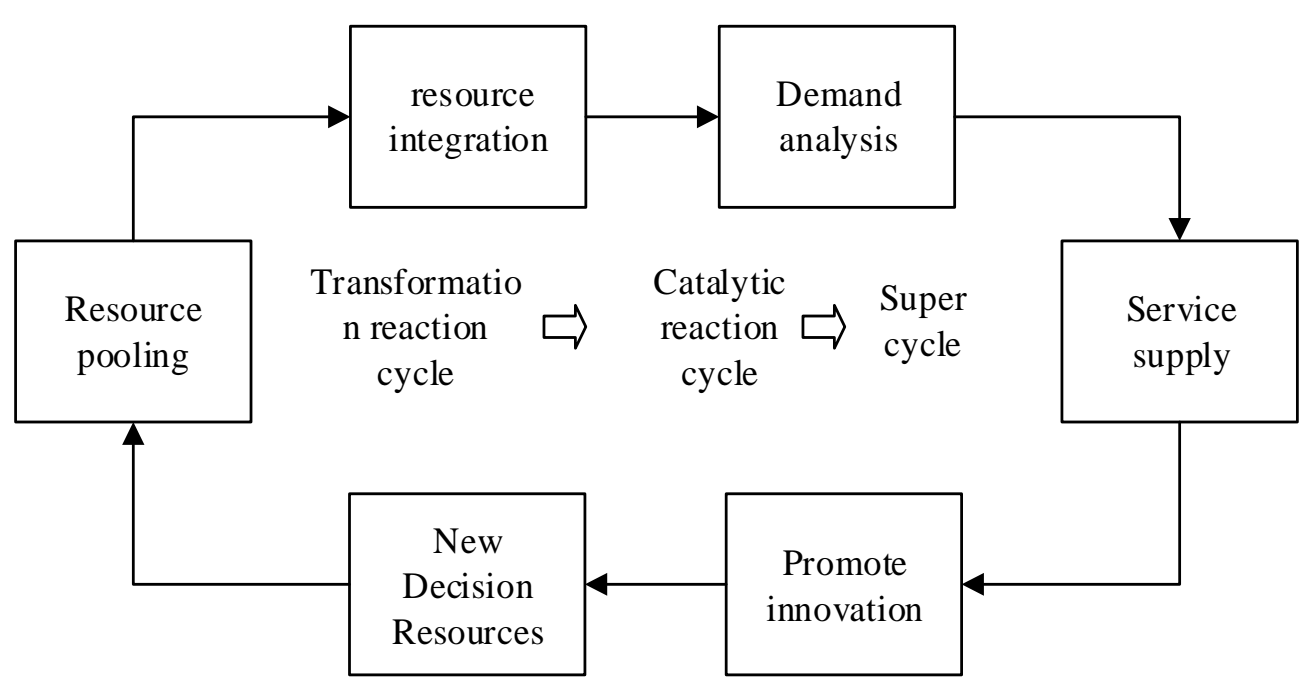

Figure 1. Supercyclic process 
Among the decision-making problems faced by the big data alliance, it is the alliance members who have an impact on the decision-making task and play a leading role in the process of decision-making problem-solving. The knowledge reserves, capabilities, and preferences of the alliance decision-making members have a great impact on the outcome of the decisionmaking task. influences. The American management scientist H.A. Simon divides the decisionmaking process into four stages, namely the intelligence stage, the design stage, the selection stage, and the delivery stage. Complete the collection and processing of decision-making information in the intelligence phase. The design phase completes the feasibility plan based on the existing resource discovery and analysis. In the selection stage, the final plan is determined among various feasible decision-making plans. According to the four-stage model of big data value incubation and value-added, it is mapped to the big data alliance to provide users with decision support services, and the process of gestation, germination, expansion, and breakthrough of decision resources is shown in [Figure 2].

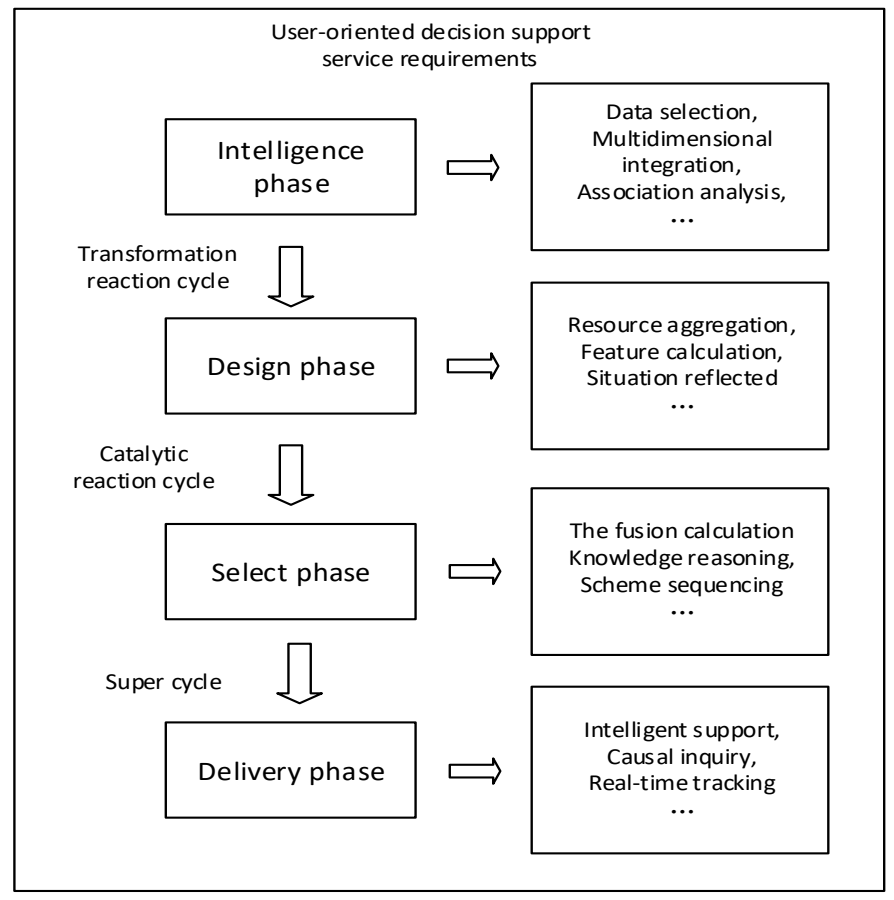

Figure 2. Service level relationship

\subsection{Big data alliance decision support service model architecture}

The Big Data Alliance uses artificial intelligence technology, big data processing technology, and other advantages based on its resources and technological advantages. According to the synergy theory alliance members in the big data alliance decision support service result generation process, the all-around realization of big data alliance decision support service plan design, processing, inspection, and other processes of communication and interaction. Mining effective and accurate information from the massive decision-making resources of the Big Data Alliance to form decision support service plans at different stages. Efficiently assist alliance users to solve their decision support service problems in specific situations, realize the value discovery process of data from knowledge to intelligence, and ultimately assist alliance users in decision-making. 
The big data alliance decision support service model uses multidisciplinary demand analysis theory to explore the real decision support service needs of users in the big data alliance, and further describe the needs of the alliance users, including the reasons, processes, and expected goals of the demand for decision support services. Then clarify the direction of decision-making resource integration. According to the core decision support service requirements, the Big Data Alliance uses intelligent resource transmission technology to efficiently transmit the decision resources required for decision support services, and accurately realize the resource perception and access of the cloud. Make preparations for the integration of decision support service resources, which can effectively integrate multi-dimensional data resources. Realize the fusion calculation of the decision resources required in the decision support service, thereby discovering the implicit and causal relationship between the resources required by the decision support service.

The main body of the big data alliance decision support service refers to the provider and receiver of the decision support service. It mainly includes the decision support service provider and the alliance user. The two main bodies are the decision support service provider and the decision support service user. Based on the characteristics of big data alliance user needs, including two situations of complete and incomplete user demand information, a process model for the decision support service of the big data alliance is constructed. As shown in [Figure 3].

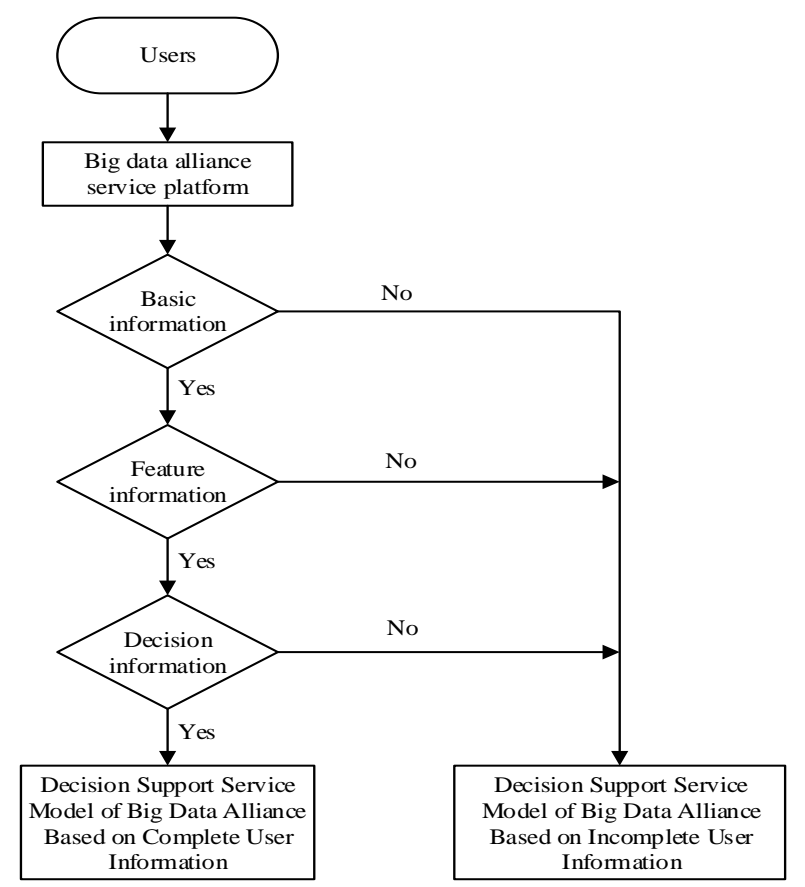

Figure 3. Big data alliance decision support service process

The decision support service provided by the Big Data Alliance relies on service-oriented thinking, combined with the service hierarchy structure, and designed a hierarchical service model that conforms to the decision support system. The purpose is to make it clear that the Big Data Alliance provides users with the required decision support services. The decision support service system architecture of the Big Data Alliance consists of four levels: service support layer, service coordination layer, the service core layer, and service auxiliary layer. 
The Big Data Alliance promotes the effective transfer and utilization of data resources and enhances the density and activity of data resources based on its advantages in gathering data resources from multiple parties. The heterogeneous data contained in the data resource pool is aggregated, correlated, and fused, to better provide auxiliary support for user decision-making and realize the value-added of data resources. In the process of providing decision support services to users by the Big Data Alliance, it is necessary to provide users with the required decision support services in an efficient and targeted manner to meet the diverse needs of users at different levels of decision support services. The final results of decision support services are delivered to users in the form of solutions to meet the differentiated decision-making needs of users. The big data alliance decision support service model is flexible and convenient. The core idea of its design is to satisfy the decision support service requests of different users as much as possible. This article aims at the complete and incomplete situation of the user's demand information according to the user's demand characteristics in different periods in the decisionmaking process. The big data alliance decision support service model is divided into the big data alliance decision support service model based on complete user information and the big data alliance decision support service model based on incomplete user information. [Figure 4] is the framework of the big data alliance decision support service model.

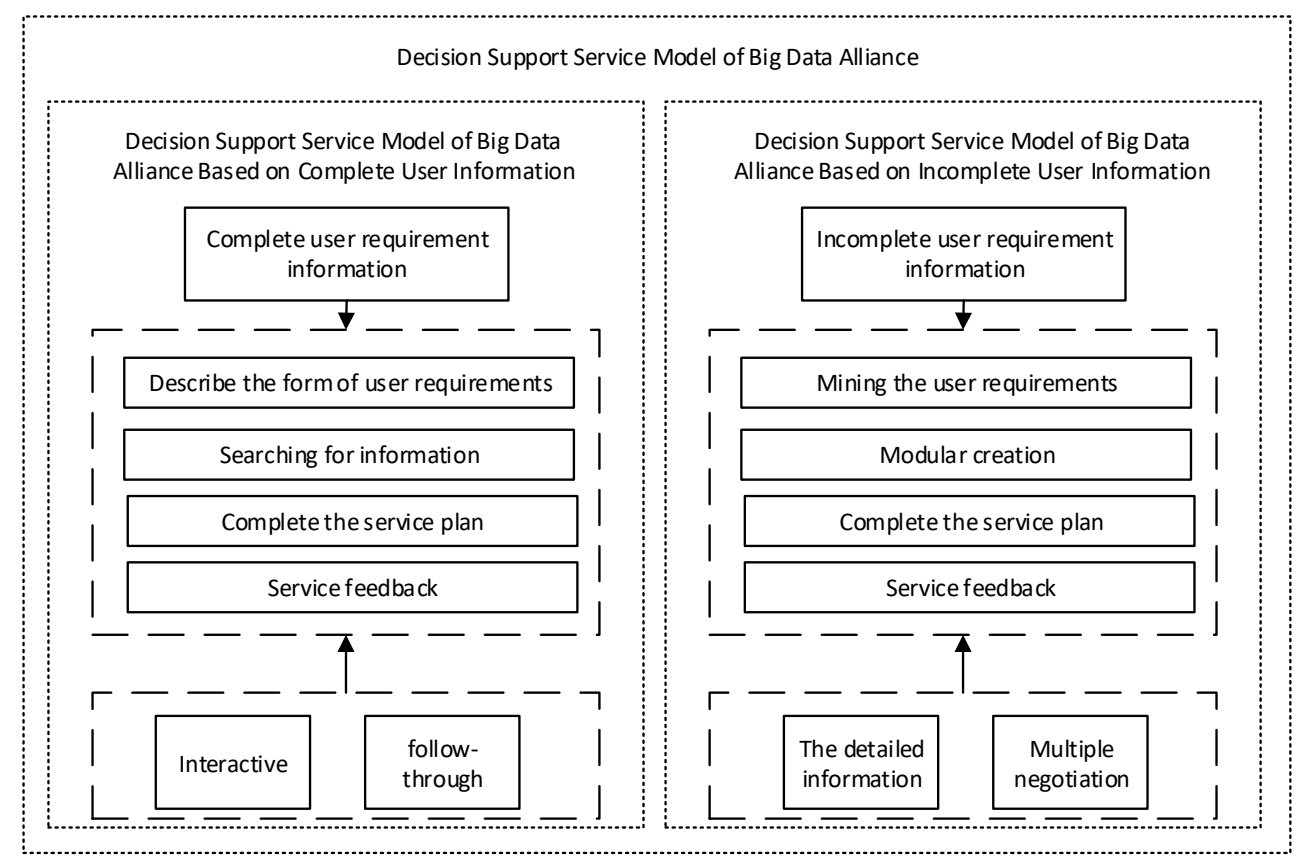

Figure 4. Service pattern framework

\section{Big data alliance decision support service model based on complete user information}

\subsection{Description of user requirements}

(1) User basic information description. The big data alliance decision support service model is based on complete user information. Users can prepare to describe the basic information of their decision support services, including what decision support services need to do, the purpose 
of decision support services, and how to provide decision support services. After the Big Data Alliance receives basic user information, it analyzes and processes it.

(2) User demand information description Big Data alliance user demand description refers to the establishment of a scientific decision support range demand expression model. The user's decision support service is expressed in an appropriate way, which is conducive to the big data alliance to conduct the resource search and matching activities required by the decision support service. Due to the diversified types of alliance users, the expression types and storage structures of information transfer between different members are quite different, which is not conducive to the processing of demand information by the big data alliance and reduces the efficiency of decision support services.

The quality of the big data alliance's decision support service determines the user's satisfaction, so meeting the user's demand for decision support service quality is an important prerequisite for improving the user's satisfaction of the big data alliance's decision support service. The big data alliance decision support service quality index based on complete user information mainly includes decision support service cost, response time, and reliability, which can be expressed as $Q o S=<C(S)$, ( ) $T S, R(S)>$. Among them, $C(S)$ represents the cost of decision support services, $T(S)$ represents the time of decision support services, and $R(S)$ represents the reliability of decision support services.

(1) Cost of decision support services. The cost of a decision support service refers to the cost that users need to pay. Decision support service cost $C(S)(\mathrm{C} 1$ is the cost of decision support service delivery, $\mathrm{C} 2$ is the cost of decision support service in operation) is expressed as follows:

$$
C(S)=C_{1}+C_{2}
$$

(2) Decision support service response time. The response time of decision support services reflects the capabilities of the Big Data Alliance, which is the time it takes for users to submit a decision support service request from the service port to obtain a decision support service plan. Set the response time of the big data alliance decision support service based on complete user information as $T(S), T_{\text {pro }}(i)$ is the processing time of the decision support service, $T_{\text {trans }}(i)$ is the time from the submission of the decision support service to the receipt of the result, $n$ represents the number of executions of the decision support service. The response time formula of the big data alliance decision support service based on complete user information is as follows:

$$
T(S)=\sum_{i=1}^{n}\left(T_{\text {pro }}(i)+T_{\text {trans }}(i)\right) / n
$$

(3) Reliability of decision support services. Reliability refers to the ability of big data alliance decision-making services based on complete user information to execute during operation. Assuming that the number of times of executing the big data alliance decision support service $S$ between $(0, t)$ is $n$, and the number of normal executions is $n_{i}$, the reliability of the big data alliance decision support service based on complete user information is expressed as follows:

$$
R(S)=n_{i} / n
$$

\subsection{Decision support service information search and matching}

To improve the efficiency of big data alliance user demand and decision support service search, a search and matching model of decision support service demand is proposed. 
(1) Basic information search. According to the user's decision support service requirements, the search for the required decision resources in the decision support service virtual pool marks the beginning of the decision support service search.

(2) Domain information search. After searching the basic information of decision support services, according to the definition and description of decision support service requirements, the search is mainly carried out from the information of decision support services.

(3) State information search. After searching for information in the decision support service field, within the scope defined by the user's decision support service requirements, the main search is for the status of the decision support service to clarify the service characteristics that the decision support service can provide.

After the above three levels of search, the user-oriented decision support service needs are matched and the decision support service resources that meet the user's decision support service needs are matched.

\subsection{Formation and delivery of decision support service plans}

The service plan formation process is based on obtaining a set of decision support services to provide users with high-quality decision support service plans. This paper describes the problem of decision support service composition, and then establishes and solves the optimization model of decision support service composition. In the Big Data Alliance, demandbased task flow means selecting and combining decision support service resources from a decision support virtual data resource pool. Decision support service resources are processed by the big data alliance decision support system, and different alliance members extract, clean, and transform the decision resources. In the need of decision-support programs, different members call the corresponding method library, model library, and knowledge base according to their tasks to complete their tasks. At the same time, it coordinates the information exchange between the database system, the model library system, and the method library system, and provides functions such as information collection, problem identification, model analysis, and calculation for the big data alliance decision support service, and finally forms a decision support service plan.

Service delivery is to fulfill the criteria and activities of the user's decision support service. A single decision support service is selected from the data resource pool of the decision support service and converted into a sequential service using existing technology. In the process of providing decision support services to users by the Big Data Alliance, what users ultimately purchase and use is a decision support service plan, and what the Big Data Alliance finally delivers to users is a complete set of decision support service plans. Based on the actual situation of the Big Data Alliance providing users with decision-support services, the Big Data Alliance will deliver the corresponding decision support service plan according to user needs, and the user will pay for the service according to the agreement. In the process of decision support service delivery, management of qualification and identity authentication, service level agreement confirmation, decision support service application, change, etc. is carried out. The big data alliance will also form a service list that can be queried by users. As the main body of decision support services, the big data alliance and users can use the service monitoring tools of the big data alliance to realize the collaborative management and control of the delivery of decision support services to discover services. The faults in solution delivery shall be solved in time. 


\section{Big data alliance decision support service model based on incomplete user information}

\subsection{User demand mining}

The speed of data generation in the information age is extremely fast, and user needs have also changed with the characteristics of diversity and randomness. Due to the complexity of decision-making issues and other reasons, users may not realize or fail to express their needs clearly, which requires external guidance and assistance. Mining deep-level decision support service needs. Based on the user context experience theory, the decision support service platform is used to conduct mining statistics from multiple dimensions of users' browsing behavior, purchasing habits, and personality characteristics, and combine the actual situation of user needs to construct a conceptual model of user needs identification of the Big Data Alliance. The Big Data Alliance obtains basic data information such as user attribute information, browsing records, demand question domains, guided question, and answer, etc. through users' search and browsing records on the decision support service platform, and combines data processing technologies such as machine learning algorithms and artificial neural networks. method. Realize the user's multiple dimensions fuzzy decision support service needs to display the results, discover the potential contact rules of the user's needs, and then extract the user's hidden information.

\subsection{Formation and delivery of decision support service plans}

Baldwin et al. pointed out that modularity is the process of constructing complex businesses and products through multiple independently functioning units. Applying modularity to decision support services based on incomplete user information, the modularity of providing decision support services is defined as according to the relationship between decision support service links and elements, members divide labor and collaborate to construct service modules. The various sub-modules form the decision support service information required by users through the transmission of information and spatial rules.

Based on the extension theory, this paper constructs the extension service model of the big data alliance decision support service model based on incomplete user information. First define the contradiction problem, the incomplete user information, and the unbalanced contradiction between the decision support service plan and the use of decision support service module primitives. According to the decision support service demand of incomplete user information, it can be extended and transformed, and finally, a targeted decision support service plan is formed.

(1) Defining contradictory issues, in the process of providing decision support services for users, the Big Data Alliance provides not only products, nor a single service, but a solution that integrates products and services organically.

(2) Matter, Matter, and Relational Elements of the Big Data Alliance Under the coordination of unified rules, the members of the Big Data Alliance form a dynamic network with low transaction costs through the division of labor and collaboration. The ordered triple $\mathrm{R}=(\mathrm{N}, \mathrm{C}$, $\mathrm{V})$ formed by taking things $\mathrm{N}$ as the object, $\mathrm{C}$ as the characteristic, and the magnitude $\mathrm{V}$ of $\mathrm{N}$ to $\mathrm{C}$, is called the basic element describing things, then the matter element of the big data alliance. The expression is:

$$
R_{\text {Big Data Alliance }}=R_{\text {Member } 1}+R_{\text {Member } 2}+\cdots+R_{\text {Member } k}+\cdots R_{\text {Member } n}
$$


among them,

$R_{\text {Member } k}=\left(N_{\text {Member } k}, C_{\text {Member } k}, V_{\text {Member k }}\right), \quad C_{\text {Member k }}=\left[\begin{array}{c}C_{k 1} \\ C_{k 2} \\ \ldots \\ C_{k n}\end{array}\right], \quad V_{\text {Member k }}=\left[\begin{array}{c}V_{k 1} \\ V_{k 2} \\ \ldots \\ V_{k n}\end{array}\right](k=$

$1.2, \ldots, n)$

In the same way, for the business cooperation relationship between member companies in the big data alliance, the matter element $(I)$ and relationship element $(Q)$ of the alliance can be established.

(3) Extensible transformation, based on the core needs of users, based on the big data alliance decision support service architecture. Implement extension transformation to service module primitives, adjust and configure service elements and service content in time. Establish the mutual connection between the user's core needs and the service plan, and finally output the extension service decision support plan. The extension service model of the big data alliance.

In the process of delivering decision support services to users in the Big Data Alliance, continuous interaction with users is required. According to the actual operation of the big data alliance and the decision-making needs submitted by users, the big data alliance decision support service platform provides a variety of channels and ways to purchase decision support services. Browse and operate from various mobile terminals, such as computer desktops, mobile phones, tablets, etc., to facilitate users to browse and receive service plans. The Big Data Alliance establishes and saves documents based on resource browsing and usage, including archiving transaction information in the process of decision support service delivery. The big data alliance and users can keep abreast of the progress of each stage of the service process and realize the collaborative management and control of decision support services.

\section{Conclusion}

Through the analysis of the big data alliance, decision support system, and decision support service levels, this paper reveals the reasons for the formation of the big data alliance, the decision support service process, and the elements and frameworks of the big data alliance decision support service model, combined with the inherent characteristics of the big data alliance. The characteristics and background have constructed a big data alliance decision support service model. The research on the big data alliance is still in its infancy. Most of the existing research results are based on strategic alliances, knowledge alliances, industryuniversity-research alliances, and data alliances. The key technologies, architectures, and data resource sharing research on utilization are still seldom carried out. As the core of the big data alliance, data resources play an important role in the construction of the big data alliance, the stability of the alliance, and the cooperation of alliance members. Starting from the analysis of the big data industry chain, the data resource service of a single big data enterprise is extended to the field of big data alliances. Relying on the high-performance computing capabilities of the big data alliance to build a big data alliance decision support service model, and strive to improve the big data alliance decision support service efficiency and corporate competitiveness will become the future research direction. 


\section{References}

[1] A. Marchand, A. Donald, and J. Peppard, "Why IT fumbles analytics," Harvard Business Review, vol.91, no12, pp.104-108, (2013)

[2] J. Akoka, W. I. Comyn, and N. Laoufi, "Research on big data: A systematic mapping study," Computer Standards and Interfaces, vol.54, no.89, pp.105-115, (2017)

[3] A. R. Ali, I. A. Zualkernan, and M. Rashid, "A smart home energy management system using IoT and big data analytics approach,” Transactions on Consumer Electronics, vol.63, no.4, pp.426-434, (2018)

[4] E. Correa, E. Inga, and J. Inga, "Electrical consumption pattern base on meter data management system using big data techniques," International Conference on Information Systems and Computer Science, pp.334-339. (2018)

[5] E. Mckayand M. D. Mohamad, "Correction to big data management skills: Accurate measurement," Research and Practice in Technology Enhanced Learning, vol.13, no.1, pp.8-9, (2018)

[6] N. Golov and L. Ronnback, "Big data normalization for massively parallel processing databases," Computer Standards and Interfaces, vol,54, no.3, pp.86-93, (2017)

[7] C. Marco and P. Anit, "How organizations leverage big data: A maturity model, Industrial Management and Data Systems, vol.116, no.8, pp.1468-1492, (2016)

[8] G. Manco, E. Ritacco, and P. Rullo, "Fault detection and explanation through big data analysis on sensor streams," Expert Systems with Applications, vol.87, no.19, pp.141-156, (2017)

[9] M. I. Pramanika, R. Y. Lau, and H. Demirkan, "Smart health: Big data-enabled health paradigm within smart cities," vol.32, no.2, pp.1-11, (2017)

[10] J. S. Johnson, S. B. Friend, and H. S. Lee, "Big data facilitation, utilization, and monetization: Exploring the 3vs in a new product development process," Journal of Product Innovation Management, vol.34, no.5, pp.2332, (2017)

[11] O. E. Nils and B. Heidi, "Use of big data in project evaluations," International Journal of Managing Projects in Business, vol.8, no.3, pp.491-512, (2015)

[12] S. Chahine, K. M. Kulasegaram, and S. Wright, "A call to investigate the relationship between education and health outcomes using big data," Academic Medicine Journal of the Association of American Medical Colleges, vol.93, no.6, pp.1-2, (2018)

[13] K. S. Fontaine, "The research data alliance," AGU Fall Meeting. AGU Fall Meeting Abstracts, pp.112-116, (2015)

[14] A. Treloar, "The research data alliance: Globally coordinated action against barriers to data publishing and sharing," Learned Publishing, vol.27, no.5, pp.9-13, (2016)

[15] A. P. Empster, "Upper and lower probabilities induced by a multivalued mapping," The Annals of Mathematical Statistics, vol.38, no.2, pp.325-339

[16] G. C. Rota, "A mathematical theory of evidence," G. Shafer, Princeton University Press, Advances in Mathematics, vol,24, no.3, pp.341-341

[17] Z. Hua, B. Gong, and X. Xu, "A DS-AHP approach for multi-attribute decision making problem with incomplete information," Expert Systems with Applications, vol,34, no.3, pp.2221-2227, (2008)

[18] S. Y. Hwang and W. S. Yang, "On the discovery of process models from their instances," Decision Support Systems, vol,34, no.1, pp.41-57, (2003)

[19] M. C. Rousset and C. Reynaud, "Knowledge representation for information integration,” Information Systems, vol.29, no.1, pp.3-22, (2004)

[20] A. G. Pateli, "Decision making on the governance of strategic technology alliance," Management Decision, vol.47, no.2, pp.246 -270, (2009) 